\title{
Young women's voices and HIV/AIDS in Uganda
}

\section{Article Type: Guest editorial From: Journal of Health Organization and Management, Volume 24, Issue 5}

\section{Introduction}

Despite the many studies of HIV/AIDS in Uganda and other African countries, there is little in the literature which connects directly with young women's experiences, representations and voices (Waite and Conn, 2010, forthcoming). A research programme, on this theme, was conducted by the guest editors, and a group of British medical students, in partnership with Straight Talk Foundation (STF), Uganda. STF is a health communication NGO working with young people and communities to promote safe sex in the context of the HIV/AIDS epidemic in Uganda. STF's experience of working with young people is that, in some Ugandan cultures and locations, young men demonstrate confidence and are vocal, yet young women remain silent and have little visibility. A starting point for the research, therefore, was recognition that young women's voices were not being heard for the purposes of HIV prevention. The research aimed, through use of participatory methodologies (Cornwall and Jewkes, 1995), to focus strongly on young women's voices: in this case eliciting representations of their everyday lives in the context of HIV/AIDS. Bettina Aptheker $(1989$, p. 39) provides a supporting rationale for the study of women's representations of their daily lives: "If we map what we learn, connecting one meaning or invention to another, we begin to lay out a different way of seeing reality. This way of seeing is what I refer to as women's standpoint". Learning from women about their lives, focusing strongly on their standpoint, brings us closer to a different kind of knowledge; one that not only informs us in a different way (Harding, 1991, 2004), but also one that may have greater potential for empowerment (Parpart et al., 2002). For the purposes of HIV prevention, we argue here that exploring young women's lives through their voices, as well as through the voices of young men, can offer a contribution to positive and empowering change.

\section{Hearing the voices of young women in Uganda and HIVIAIDS}


In sub-Saharan Africa, the HIV/AIDS pandemic, now into its third decade, continues to be a priority population health problem with more than half of new infections among the under-24 years age group, 75 per cent of who are young women (Bruce and Hallman, 2008). The scale and trends in the pandemic vary considerably by country and subregion: with Southern Africa experiencing highest prevalence rates (approximately 15 per cent in adults aged 15-49 years); West and Central Africa experiencing the lowest rates (under 5 per cent); and East Africa, including Uganda, experiencing stable or declining rates for adults (at around 6 per cent) due to behaviour change and deaths among those already infected (UNAIDS, 2007). A concern for Uganda is that young women suffer from high rates of HIV/AIDS with prevalence in those aged 15-19 years (the age range of most of the participants of this research) at about 3 per cent. This is disproportionately high when compared to young men in the same age group who have a prevalence of around 0.3 per cent (Ministry of Health Uganda and ORC Macro, 2006).

Young women of Africa are known to experience multiple vulnerabilities to HIV/AIDS. Biological vulnerability is a factor for young women, due to biological immaturity leading to enhanced susceptibility to sexually transmitted infections (Piot and Bartos, 2002). Young women are at a particular disadvantage also in relation to social and economic vulnerabilities, suffering disproportionately from the negative effects of poverty and gender inequality (Mabala, 2006). These provide an environment within which young women experience educational, legal, and employment inequalities (IPPF, 2006). More specifically in relation to sexual health vulnerabilities: a legacy of historical and cultural norms has perpetuated male power and female subservience (Musisi, 1991; Tamale, 2006); there exist common practices of sexual coercion and violence, stigma and taboo, both in the home and at school (Neema et al., 2007; Tamale, 2006); and early marriage or union with older male partners puts young women at risk from HIV positive older men (Neema et al., 2004; UNICEF, 2006).

Despite the broad understanding about young women's vulnerabilities, there is limited knowledge about the particular circumstances of young women's vulnerabilities in different country contexts and across various 
cultural and social settings. This means that there is considerable scope to improve our understanding of young women's experiences, particularly in relation to their multiple positions with regard to gender, culture and educational backgrounds and the intersection of these positions (Phoenix and Pattynama, 2006). Chandra Mohanty (1991), in her classic work on the oppression of "third world women", called for an exploration of women's different experiences of vulnerability for a less homogenized, more nuanced appreciation of their lives. Such a call is clearly still required today for an approach which will be more responsive to young women's needs; especially pressing given that, by virtue of the intersection of age and gender, young women are even less visible and more voiceless than adult women (Kurz and Prather, 1995; UNICEF, 2007).

Sandra Harding proposed that the need for a women's standpoint in science stemmed from the idea that it is not about including their lives and voices, but about starting from their situation for the purposes of research; because it is their lives and their voices that should matter most for our understanding (Harding, 1991, p. 267). Our central argument in this special issue is that the lack of young women's voices in the HIVIAIDS discourse is a major concern and is related to a relative lack of work on the multiple contexts and positions of young women, and a lack of young people's voices more generally in development (Matthews et al., 1999). The gender empowerment movement in development has, over the decades, called for a much greater emphasis on women's voices, not only as a means of bringing to the fore their knowledge (for the reasons of scholarship already explored previously in terms of women's standpoint), but also as a means of furthering an empowerment agenda (Batliwala, 1994; Parpart et al., 2002). This agenda proposes that women must have the means to voice their experiences and those voices must be heard and valued for empowerment to take place. Women will then have a chance to impart their knowledge and influence others, personally, publicly and politically.

Young women's vulnerability to HIV/AIDS in relation to poverty and gender inequalities must be tackled to protect young women from infection. It is now recognised that tackling that environment of poverty 
and gender inequalities means addressing the empowerment of young women. There is a need for better knowledge about how young women can be empowered within and beyond HIV/AIDS prevention. Yet, HIV/AIDS prevention programmes have been slow to adopt empowerment approaches, despite the recognition of their importance and given the entrenched nature of women's vulnerabilities in relation to gender inequalities.

Uganda has experienced a significant decline in HIV/AIDS, with a reduction from a high prevalence, estimated at 18 per cent in the early 1990s, to approximately 6 per cent today (Ministry of Health Uganda and ORC Macro, 2006; UNAIDS, 2007). Ugandan HIV prevention policy in relation to young people, backed by strong political will at a high level, has focused on working with schools and communities using communication, education, and advocacy strategies within the widely adopted format of Abstinence, Being faithful (within union or marriage), and Condom use (ABC) (Uganda AIDS Commission, 2007). There is a sense, however, of tremendous urgency to prevent HIV/AIDS against a fear that the epidemic might grow again (Allen, 2005; UNAIDS, 2007).

While an emphasis on individual behaviours, mainly abstinence, knowledge of the disease, and use of condoms (known as ABC or Abstinence, Be Faithful, Use Condoms) has been the main HIV prevention strategy across Africa, it has been criticised on a number of counts. A criticism against the $A B C$ format, with its emphasis on abstinence, is that it is a standardised and socially unrealistic format and therefore inappropriate for the variety of circumstances experienced (Karim et al., 2009). This links to the idea, that across different cultural contexts, such a discourse has been heavily influenced by external, and internal religious, and political forces, often driven by their own agendas, rather than specific health needs (Allen, 2005). Also, it has been argued that hitherto HIV/AIDS prevention programmes have been based on traditional health promotion, which places emphasis on individual risk avoidance and behaviour change. This does not take into consideration issues such as poverty, gender inequality, lack of protective systems and practices, sexual stigma, taboos and fears, and the silencing of young people (Karim et al., 2009; Mabala, 2006; WHO, 2006). 
Fortunately, there appear to be moves towards new approaches to HIV prevention, which support different ways of knowing, although there are currently a lack of mechanisms, languages and methods for bringing the different knowledge together fruitfully (Auerbach, 2009). But what might such new approaches include? Clearly there is a place for a move away from the medicalised language of HIVIAIDS prevention, to one that is more engaging about sexuality and sexual health. This would include using positive terms and providing a basis for negating sexual stigma, taboo and fear, as well as undermining gender stereotypes (Harcourt, 2009). A further imperative is to continue to explore ways of bringing forth young people's perspectives and voices, both young women and men, in relation to HIV/AIDS. This has already begun in many countries and through innovative programmes, some of which may not have an HIV focus but rather are distinguished by being strongly focused on young people's voices (Cahill, 2006; Kafewo, 2008). Non-traditional approaches to HIV prevention might include those advocated here in terms of promoting young women's (and, as important, young men's) voices in research and interventions as partners; or as their own champions, role models and mentors; or exploring and celebrating young femininities and masculinities where it is appropriate (Cahill, 2006; Kafewo, 2008; Waite and Conn, 2010, forthcoming). Also, there is a need to actively seek ways to bring about gender equality and young women's empowerment within and beyond HIV-related programmes. The gender empowerment movement is working vigorously in Uganda (Tripp and Kwesiga, 2002), and needs to be supported to go further with greater emphasis on young women and for HIV prevention.

\section{Structure of the special issue}

The collection of papers presented here is based on six student research projects around the common theme of young women's voices in the context of HIV/AIDS in Eastern Uganda. The students, who were part way through their medical education, explored with young women (and in one paper with young men) different aspects of their lives: work, home and family; school and sexual lives; and desires, opinions and viewpoints. 
The students received training in participatory research methods and explored issues of both researcher and participant voices. The central concepts of participatory research (PR) are that interactive methods are more appropriate than extractive methods in working with young people; that researcher and participants are partners and learning is a two way process; that participants in some way shape methods; and that the research makes a contribution towards an empowerment agenda (Cornwall, 2003; Cornwall and Jewkes, 1995). These ideas of research contrast with the biomedical paradigm students are more familiar with; that is, the researcher as scientific expert identifying risk factors which can be explained and addressed in a relatively straightforward and standardised way for the purposes of tackling disease (Inhorn and Whittle, 2001); yet with limited regard for issues of gender, power and culture. The research project, part of a Leeds medical school programme in international health, aims to provide students with valuable training in global health. This includes studying some of the global health issues that shape our world. Also, the programme focuses on a broader sense of the social and cultural determinants of health beyond individualistic and biomedical ones (Broome et al., 2007). Some of the authors presenting here refer to the positive experience of undertaking the research in enhancing their understanding of the health effects of different cultural, age and gender circumstances which contributes to their personal growth as health professionals and global citizens.

The first two papers presented focus on young women's sexual lives in two locations in Eastern Uganda.

Rebecca Nicholas's study is concerned with the environment of poverty and gender inequalities and the effects on young women's ability to protect themselves against HIV/AIDS. She finds that the participants demonstrate a good knowledge of how HIV/AIDS is transmitted. Such knowledge is often an important indication of success in health promotion. But, as her study shows, this knowledge has limited value because young women do not have sufficient power or resources to protect themselves against HIV/AIDS. This case study illustrates and highlights the WHO position which states that creating an appropriately 
protective environment is key to preventing HIV/AIDS and this requires negating the effects of gender inequality and poverty (WHO, 2006).

Manvir Kaur Hayer's study explores a very sensitive area, yet one that is crucial to investigate in this context of HIV prevention; that of young women's definitions and perceptions of sexual coercion. Hayer codesigned research methods with her participants and what emerged was the negotiated use of video, story-telling, drawings and transect walks. Participants told stories that clearly signalled the gender and culturally specific interpretation of sexual coercion. The young women distinguished between a range of acts under the umbrella term of sexual coercion; forced sex was labelled as rape whereas a variety of verbal coercions were described as "abusing" or "convincing" and may lead to "constrained sex". Hayer's study is important in that it shows us how better understandings of sexual coercion based on young women's definitions and perceptions may assist in the development of prevention programmes and provide necessary help for young women on their own terms.

Natasha Lovell takes a different direction from these papers in that she explores Ugandan young women's life expectations. This subject is important in an academic context which does not explore the desires of African young women, unlike the many studies on Western young women (Aapola et al., 2005; Harris, 2004); because of a perceived need to concentrate narrowly on disease and poverty prevention. By raising and exploring the issue of young women's expectations it highlights their position as individuals, with personal identities and desires beyond the macro goals set by countries and development agencies; and with the right to determine their lives and make personal choices. We believe that this is an important part of the agenda for young women's empowerment no matter what the social setting; given the arguments expressed previously in favour of adopting women's standpoint, listening to their voices, and having a concern for their lives and their desires for the future. The study finds that there is a mismatch between Ugandan young women's expectations and the reality of their lives. For example, they have high hopes for education and the effects of education in helping them into employment yet there are many barriers to educational attainment. Despite the hardship and 
disappointment this implies for young women today, the mismatch between current lives and aspirations perhaps reflects future possibilities within the wider social and economic changes that are taking place in Uganda.

The next two papers are linked by their different gender positions, yet touch on similar issues: that is, what drives sexual relations from the perspectives of a group of young women (Suesanne Samara) and young men (Anil Joshi).

Suesanne Samara explores the much debated notion of "transactional sex" in relation to young women and HIV/AIDS in Africa. The orthodoxy, within which there is a hidden sense of young women's collusion in their own infection, concerns the idea that young women are at high risk of HIV/AIDS because they engage in sex with older, high risk men in exchange for money and/or gifts. This phenomenon, known in Uganda as "Something for something love", is explored here noting that, while there is indeed an issue of young Ugandan women having older partners, the issue is more complex, contextual, and historically situated, than the debates would imply. Particularly useful for the debate is the call to move away from polarising young women either as passive victims who are forced to take up transactional relationships, or as calculating and sophisticated agents who use their sexuality to maximise financial gain through sex. Samara finds that neither of these stereotypes are either accurate or helpful in the fight against HIVIAIDS. She urges policy makers and practitioners to use a more nuanced understanding of transactional sex within a better understanding of gendered environments.

Anil Joshi's paper is particularly valuable here in that it is the only paper which explores young men's voices. The focus of the research was young women in Uganda, but we appreciate that young men's voices are as important as a goal of study within a framework of gender relations. Indeed, we argue for greater exploration of young people's voices in general. In this study, what emerges, are thoughts on the importance to young men of having multiple sexual partners. The young men speak of both "love" and "sex" being key in relationships for sexual pleasure and to gain all-important sexual experience, and to 
have a high degree of control in sexual relations. These attributes contribute to their sense of being "masculine". Issues of concern to them were money, having money to give to partners, manipulative young women, and parental control. These concerns dominated over health related factors, which played a limited part in their sexual lives. Joshi contributes to the agenda on young masculinities and more open and honest approaches to sexuality, sexual scripting, and the use of condoms.

Finally, Sinead Cook's paper on young women's views on sex education in school moves away from considering aspects of individual lives to exploring their voices in relation to an important element of HIV/AIDS prevention. Her study explores with a group of Scottish and Ugandan school attendees, and their perspectives on their sex education. She demonstrates that young women can have strong opinions on the matter and that listening to them is valuable in shaping HIV/AIDS prevention efforts. Cook's study contributes to a body of knowledge about the value of using small groups to elicit this kind of local information for a local response. While globally schools are and have been for some time considered a major focus for sexual health, there are particular concerns for Uganda. In the study young women call for female teachers and mentors. Yet, in Uganda teachers are predominately male (Tumushabe et al., 1999); just one important issue among others relating to the gendered and resource constrained environment of school. This study has an additional value in that it elicits young people's viewpoints across cultures, and by so doing destabilises development academia, which tends to separate out the experience of people in developed and developing communities creating an invisible wall between the two. Instead we consider that this kind of study is a call to share experiences of young people across different cultures, learning from each other, as well as informing policy.

In conclusion, there is a lack of contextually appropriate knowledge about young people in parts of Africa, especially that which reflects young people's voices and viewpoints (both young women and men). Also, there is a lack of knowledge, which engages with some difficult issues in HIV/AIDS prevention terms; especially that of gender, power, culture and sexuality and the intersections between them. We hope 
that this special issue has posed some challenges to norms of HIV prevention in relation to young women, and to young men, and given some space for their voices, opening up new possibilities for understanding and change.

\section{Acknowledgements}

The special issue draws on a research project, conducted in Uganda in 2006, titled "Increasing the effectiveness of Straight Talk Foundation (STF) Uganda programmes in relation to Young Women". This was led by the Guest Editors in partnership with STF Uganda, and with the involvement of a number of student projects. Thanks in particularly go to members of STF staff: Cathy Watson, director, and Patrick Walugembe and Evelyn Namubiru in-house researchers, for their contributions (www.straight-talk.org.ug). The project was supported by the DFID (UK)-funded "Research and Development for Effective Communicable Disease Control (COMDIS) programme" at the Nuffield Centre for International Health and Development, University of Leeds (www.comdis.org). Therefore thanks also go to the COMDIS programme managers, John Walley and James Newell, for their support. Finally, and not least, thanks go to the authors for their contributed papers and Nancy Harding, Editor of the Journal of Health Organization and Management, for her ongoing support for this special issue.

\section{About the authors}

Cath Conn Visiting lecturer at Centre for Development Studies, Auckland University, New Zealand. She is currently on sabbatical from the Nuffield Centre for International Health and Development at Leeds University, UK, and was a co-lead researcher on the project, "Increasing the effectiveness of Straight Talk Foundation (STF) Uganda programmes in relation to young women".

Louise Waite Lecturer at the School of Geography, University of Leeds. She was co-lead Researcher on the project, "Increasing the effectiveness of Straight Talk Foundation (STF) Uganda programmes in relation to young women". 


\section{Cath Conn, Louise WaiteAuthors/Guest Editors}

\section{References}

Aapola, S., Gonick, M. and Harris, A. (2005), Young Femininity: Girlhood, Power and Social Change, Palgrave Macmillan, Basingstoke

Allen, T. (2005), "AIDS and evidence: interrogating some Ugandan myths", Journal of Biosocial Science, Vol. 38, pp. 7-28

Aptheker, B. (1989), Tapestries of Life: Women's Work, Women's Consciousness, and the Meaning of Daily Experience, University of Massachusetts Press, Amherst, MA

Auerbach, J.D. (2009), "Foreword", in Mayer, K.H. and Pizer, H.F. (Eds), HIV Prevention: A Comprehensive Approach, Elsevier, Oxford, pp. $\mathrm{xi}-\mathrm{xV}$

Batliwala, S. (1994), “The meaning of women's empowerment: new concepts from action", in Sen, G. , Germain, A. and Chen, L.C. (Eds), Population Policies Reconsidered: Health, Empowerment and Rights, Harvard University Press, Boston, MA, pp. 127-38

Broome, J.L., Gordon, J.K., Victory, F.L., Clarke, L.A., Goldstein, D.A. and Emmel, N.D. (2007), "International health in medical education:

students' experiences and views", Journal of Health Organization and Management, Vol. 21 No. 6, pp. 575-9

Bruce, J. and Hallman, K. (2008), "Reaching the girls left behind", Gender and Development, Vol. 16 No. 2, pp. 227-45

Cahill, C. (2006), '“At risk'? The fed up honeys represent the gentrification of the lower East Side", Women's Studies Quarterly, Vol. 34 Nos 1/2, pp. 334-63

Cornwall, A. (2003), "Whose voices? Whose choices? Reflections on gender and participatory development", World Development, Vol. 31 No. 8, pp. $1325-42$

Cornwall, A. and Jewkes, R. (1995), "What is participatory research?", Social Science and Medicine, Vol. 41 No. 12, pp. 1667-76 
Harcourt, W. (2009), Body Politics in Development: Critical Debates in Gender and Development, Zed, London

Harding, S. (1991), Whose Science? Whose Knowledge? Thinking from Women's Lives, Open University Press, Milton Keynes

Harding, S. (2004), The Feminist Standpoint Theory Reader: Intellectual and Political Controversies, Routledge, New York, NY

Harris, A. (2004), All about the Girl, Routledge, New York, NY and London

Inhorn, M.C. and Whittle, K.L. (2001), “Feminism meets the 'new' epidemiologies: toward an appraisal of antifeminist biases in epidemiological research on women's health", Social Science and Medicine, Vol. 53, pp. 563-7

IPPF (2006), Report Card: HIV Prevention for Girls and Young Women, Uganda, International Planned Parenthood Federation (IPPF), London

Kafewo, S.A. (2008), “Using drama for school-based adolescent sexuality education in Zaria, Nigeria", Reproductive Health Matters, Vol. 16 No. 31, pp. 202-10

Karim, Q.A., Meyer-Weitz, A. and Harrison, A. (2009), "Interventions with youth in high-prevalence areas", in Mayer, K.H. and Pizer, H.F. (Eds), HIV Prevention: A Comprehensive Approach, Elsevier, Oxford

Kurz, K.M. and Prather, C.J. (1995), Improving the Quality of Life of Girls, UNICEF, New York, NY

Mabala, R. (2006), "From HIV prevention to HIV protection: addressing the vulnerability of girls and young women in urban areas", Environment and Urbanisation, Vol. 18 No. 2, pp. 407-32

Matthews, H., Limb, M. and Taylor, M. (1999), "Young people's participation and representation in society", Geoforum, Vol. 30, pp. 135-44 
Ministry of Health Uganda and ORC Macro (2006), Uganda HIV/AIDS Sero-behavioural Survey 2004/2005, Ministry of Health Uganda and ORC Macro, Kampala and Calverton

Mohanty, C.T. (1991), “Under Western eyes: feminist scholarship and colonial discourses", in Mohanty, C.T. (Ed.), Third World Women and the Politics of Feminism, Indiana University Press, Bloomington and Indianapolis, IN, pp. 51-80

Musisi, N.B. (1991), “Women, 'élite polygny', and Buganda state formation", Signs: Journal of Women in Culture and Society, Vol. 16 No. 4, pp. $757-86$

Neema, S., Moore, A.M. and Kibombo, R. (2007), Adolescents' Sexual and Reproductive Health: Qualitative Evidence of Experiences from Uganda, The Alan Guttmacher Institute, New York, NY

Neema, S., Musisi, N. and Kibombo, R. (2004), Adolescent Sexual and Reproductive Health in Uganda: A Synthesis of Research Evidence, The Alan Guttmacher Institute, New York, NY

Parpart, J.L., Rai, S.M. and Staudt, K. (2002), Rethinking Empowerment: Gender and Development in a Global/Local World, Routledge, London

Phoenix, A. and Pattynama, P. (2006), "Intersectionality", European Journal of Women's Studies, Vol. 13 No. 3, pp. 187-92

Piot, P. and Bartos, M. (2002), "The epidemiology of HIV and AIDS", in Essex, M. , Mboup, S. , Kanki, P.J. , Marlink, R.G. and Tlou, S.D. (Eds), AIDS in Africa, Kluwer Academic/Plenum, New York, NY

Tamale, S. (2006), “Eroticism, sensuality and 'women's secrets' among the Baganda", IDS Bulletin, Vol. 37 No. 5, pp. 89-97

Tripp, A.M. and Kwesiga, J.C. (2002), The Women's Movement in Uganda: History, Challenges and Prospects, Fountain, Kampala

Tumushabe, J., Barasa, C.A., Muhanguzi, F.K. and Otim-Nape, J.F. (1999), Gender and Primary Schooling in Uganda: Partnership for 
Strategic Resource Planning for Girls' Education in Africa, Institute of Development Studies, Brighton

Uganda AIDS Commission (2007), National HIV \& AIDS Strategic Plan 2007/8-2011/12, Uganda AIDS Commission, Kampala

UNAIDS (2007), Epidemic Update, Joint United Nations Programme on HIV/AIDS (UNAIDS) and World Health Organization (WHO), Geneva

UNICEF (2006), Report on the Situation of Children and Women in Uganda, UNICEF, New York, NY

UNICEF (2007), The State of the World's Children 2007: Women and Children - The Double Dividend of Gender Equality, UNICEF, New York, NY

Waite, L. and Conn, C. (2010), “Creating a space for young women's voices: using 'participatory video drama' in Uganda", Gender, Place and Culture (forthcoming)

WHO (2006), Preventing HIV/AIDS in Young People: A Systematic Review of the Evidence, World Health Organization, Geneva 